\title{
Non-Linear Analysis of a Two Post Roll-Over Protective Structure for Motor Grader
}

\author{
Kumar V, G. Mallesh, Radhakrishna K R
}

\begin{abstract}
Roll over protective structure (ROPS) is a critical passive safety system of any off-highway equipment. The ROPS is one of the mandatory DGMS requirements and structure is expected to withstand the impact force and maintains the safe space for operator survival during rollover accident. In the present research work, attempts are made to study the non-linear behavior of a two-post roll over protective structure of motor grader having $25 T$ Gross Vehicle Weight (GVW) by using Finite Element Analysis (FEA). In order to enhance the energy absorbing capacity and to have better performance of ROP structure, an interweave energy absorber was introduced inside the ROPS column. CAD model of ROPS was made by using Pro-E modeling software and non-liner analysis was carried by using LS-Dyna software. Non-linear analysis used to compute the maximum deformation and von-misses stress and energy absorption with respect to the lateral, vertical and longitudinal load. Non-linear analysis was carried out for each load case and studied the behavior of ROPS structure. Among all the load conditions, the lateral impact load is a vital role with respect to the energy absorption criteria. The result of non-linear analysis is appreciably par with the standard ISO: 3471(2008) E ROPS performance.
\end{abstract}

Keywords: Finite Element Analysis, Gross vehicle Weight, Interweave, Roll over protective structure.

\section{INTRODUCTION}

Looking into the growth in the mining and construction sector, there is a great requirement of all the safety systems of vehicle. Among all the system, ROPS criteria has played a major role with respect to the operator life. Therefore, it has become a mandatory requirement in Directorate General of Mines Safety (DGMS) in India for the all mining machineries. The probability of roll-over of vehicle is high due to the poor haul road profile and other factors such as unbalance of center of gravity (CG) and operating at high gradient and uneven terrain condition [1] and [2].

Fig.1 shows the Motor Grader is widely used in mining and construction sectors to carry out earth moving activities like

Revised Manuscript Received on April 25, 2020.

* Correspondence Author

Kumar V*, Research Scholar, Department of Mechanical Engineering, Sri Jayachamarajendra College of Engineering, Mysore, India. Email: kumarvaradaraj1973@gmail.com

Dr. G. Mallesh, Professor, Department of Mechanical Engineering, Sri Jayachamarajendra College of Engineering, JSS Science and Technology University, Mysore, India. Email: mallesh@sjce.ac.in

Radhakrishna K R, Executive Director, BEML Limited, Bangalore, Karnataka, India. Email: edq@beml.co.in

(c) The Authors. Published by Blue Eyes Intelligence Engineering and Sciences Publication (BEIESP). This is an open access article under the CC BY-NC-ND license (http://creativecommons.org/licenses/by-nc-nd/4.0/) grading, leveling, ice removal, bank cutting, and maintenance terrains, uneven road surfaces and worst climatic conditions, with these conditions that creates more possibility of rollover accidents. Operator safety and comfort is the highest priority in mining equipment design. ROPS structure is steel frame with either two or four structural posts which are usually attached to these vehicles above the operator's cabin for resisting moment during rollovers [4]. Indian mines records considerably higher accident and fatality rates compared to USA and South Africa [5]. A few literatures on ROPS design reveals that Rollover Protective Structure may be an integral part of the cabin or external independent structure which is kept outside the cabin. It is expected to withstand the highest impact load and absorb the energy generated during the rollover. Another important criterion is the ROPS column should not deform by extending into the operator safe/survival zone, which is known as Deflection Limiting Volume (DLV) as per the standard ISO: 3164 [7]. The strength of ROPS is directly connected to the gross vehicle weight $(\mathrm{GVW})$ of the equipment. The ROPS structural characteristic and performance varies with the configuration and application of the equipment. In reality, the testing of ROPS is time consuming process, tedious task and high cost involved. Therefore, some literatures suggested a few alternative methods that end results be nearing to the actual physical test result. The alternate method such as simulating modelling technique is an ideal concept that could be used. Continues effort has been made to develop an efficient and reliable computer based numerical technique in order to replace the costly and time-consuming physical

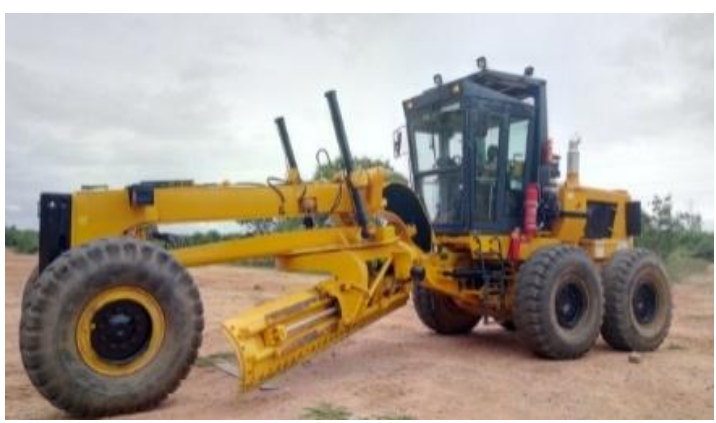

Fig. 1. Motor Grader

testing of ROPS. The result obtained from series of comparative studies made by the researcher on ROPS with a good correlation between virtual and physical testing shows that virtual simulation technique is reliable with use of proper care [1] \& [2]. It is evident from the OSHA, USA that average $16 \%$ of failure was noticed in the motor grader equipment alone [3].

Published By:

Blue Eyes Intelligence Engineering
\& Sciences Publication 


\section{Non-Linear Analysis of a Two Post Roll-Over Protective Structure for Motor Grader}

In this present study attempt has made to understand the non-linear behavior, strength and energy absorption capacity of compact ROPS for motor grader application.

\section{ROPS LAYOUT WITH DLV}

The novelty in this work is by implementing the interweave energy absorber inside the ROPS column which will enhance the energy absorbing capacity of the structure. This energy absorption technique helps in conversion of partial kinetic energy in to another energy form; therefore, the ROPS structure become compact and meets the standard criteria.

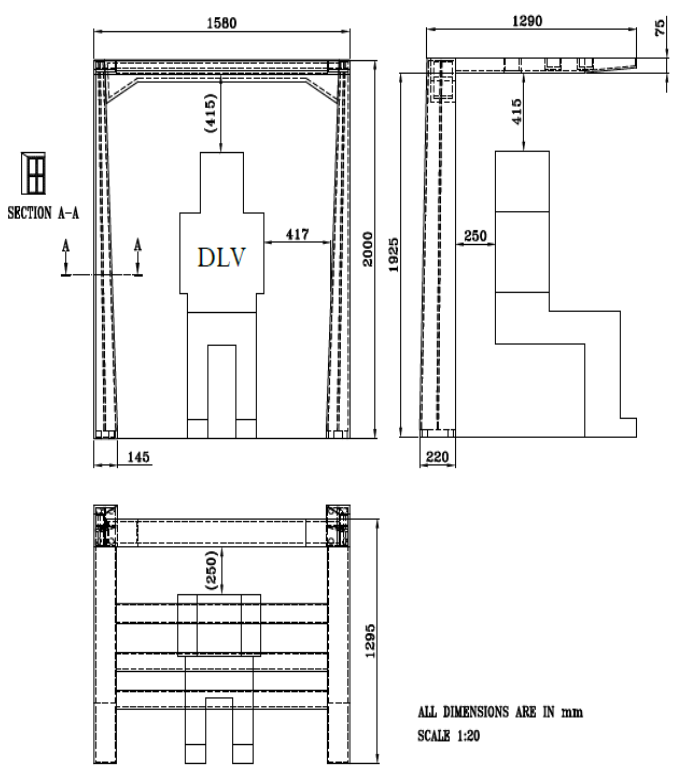

Fig. 2. Two post ROPS with DLV

Fig.2 shows layout of two post rollover protective structure with the interweave cross section. In this study, ROPS was designed with two posts cantilevered hallow uniform variable rectangle cross section with dimension $220 \times 122 \times 10 \mathrm{~mm}$. The energy absorber interweave plate of thick $10 \mathrm{~mm}$ was introduced inside column along its length. Further to strengthen, ' $U$ ' shape formed plate of 100 x $100 \mathrm{x}$ $10 \mathrm{~mm}$ was provided in between columns in horizontal at the top portion of ROPS. The whole ROPS structure was integrated as a single structure by adopting proper connectivity and welding of all the individual plates and sub-structures.

\section{ROPS MATERIAL}

The plate material used in this study for ROPS is indigenously developed high strength structural steel SAILMA 410 H equivalents to IS: 2062:2011, [8] as shown in Table I

Table- I: Mechanical properties of ROPS

\begin{tabular}{|c|c|c|c|c|}
\hline $\begin{array}{c}\text { Mechanical } \\
\text { Properties }\end{array}$ & $\begin{array}{c}\text { Tensile } \\
\text { strength, } \\
\text { MPa }\end{array}$ & $\begin{array}{c}\text { Yield } \\
\text { Strength, } \\
\text { MPa }\end{array}$ & $\begin{array}{c}\% \\
\text { Elongation }\end{array}$ & $\begin{array}{c}\text { Poisson' } \\
\text { s ratio }\end{array}$ \\
\hline $\begin{array}{c}\text { SAILMA } \\
410\end{array}$ & 540 & 410 & 21 & 0.3 \\
\hline
\end{tabular}

The stress-strain curve shown in Fig.3 indicates the ductile material behaviour with the plastic deformation start point and the maximum load. This curve will be input data to carry out non-linear analysis.

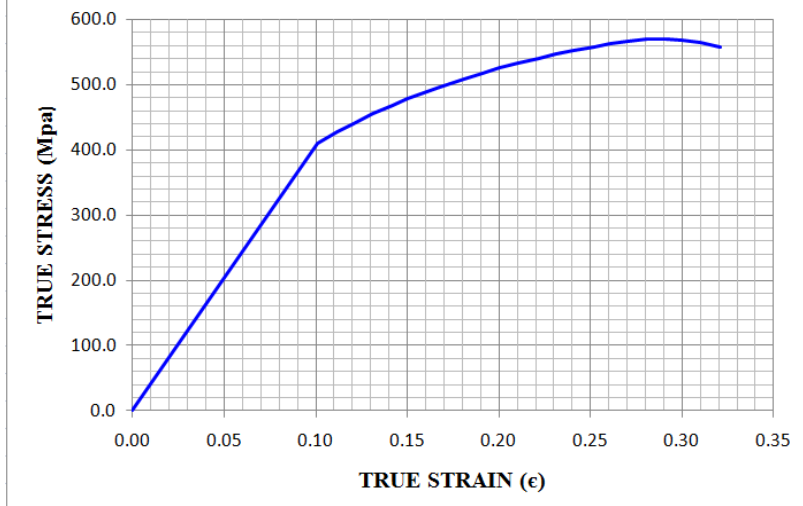

Fig. 3. shows the stress-strain of SAILMA $410 \mathrm{H}$

\section{COMPUTATIONAL SIMULATION OF ROPS}

\section{A. FEA Model}

The first and foremost step in order to carry out the simulation of ROPS is the creating the CAD model. In this study, 3D model of ROPS was developed using 3-D modelling software. Before exporting into the CEA software, the geometry clean-up activities such as removing of extra surfaces, datum planes, edges etc. was carried out in the CAD software itself and later it was converted into the neutral format.

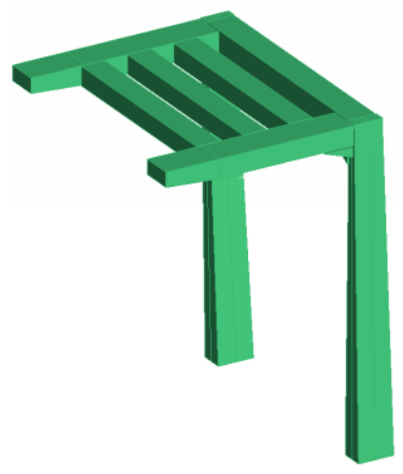

Fig. 4. Geometric 3D models of Two Post Rollover structure

Fig.4 shows the 3D model of ROPS. Meshing was done by ANSA pre-processor software and connectivity of nodes and individual elements was cross-checked and also a good quality of meshing was ensured. Based on the literature survey study, it was revealed that the quadrilateral shell element will provide the better simulation results as compared to other element in case of non-linear analysis. Therefore, in this analysis, quadrilateral element was assigned for the ROPS which is having four nodes with six degree of freedom (DOF) per node. The global mesh size was accorded with size $10 \mathrm{~mm}$ which is a finer element that will provide the better convergent result. The complete ROPS was meshed with total number of 79301elements. Fig.5 shows the FE model of ROPS. The mesh model was imported into the solver LS-Dyna software to carry out non-linear behavior of ROP. The final results were viewed using META v12.5 post processor.

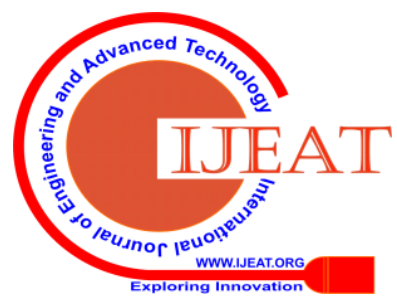




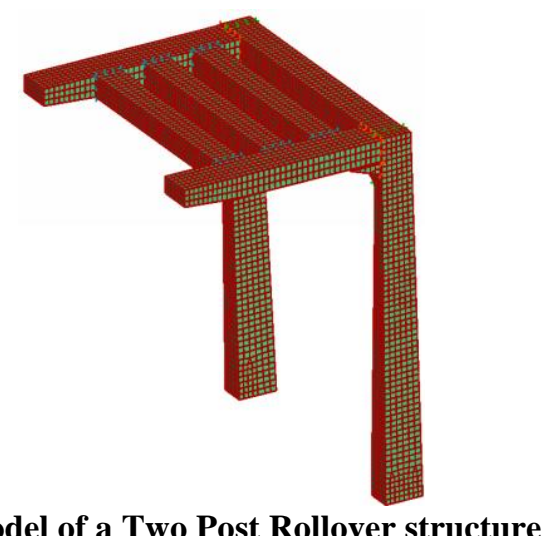

FE Model of a Two Post Rollover structure

\section{B. Boundary Conditions}

The boundary condition was in-line with the real condition of ROPS mounted on the main frame of motor grader. The bottom portion of ROPS was constrained in all the degree of freedom (DOF). Fig.6 shows the FE model with boundary condition. This boundary condition was considered so that the all loads such as lateral, vertical and longitudinal will resist the roll-over failure.

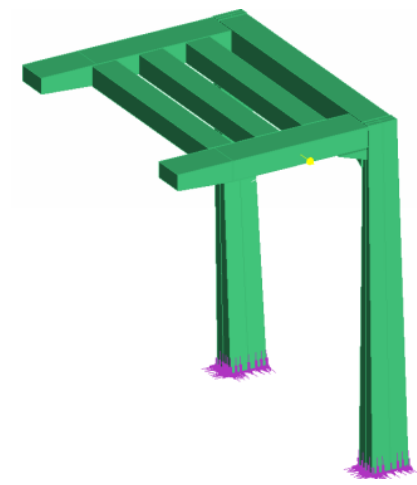

Fig. 5. FE model with boundary condition

\section{LOADING CONDITIONS}

Fig. 7 represents the lateral, vertical and Longitudinal load acting on the ROPS structure.

ROPS analysis was carried out as per ISO: 3471-2008 E standard by considering all the three-load condition such as lateral, vertical and longitudinal. The total machine mass is $25750 \mathrm{~kg}$. As per standard, for the mass of an equipment ranging from $2140 \mathrm{~kg}$ to $38010 \mathrm{Kg}$ the given formulas are used to determine the ROPS loads and energy absorption condition. The load calculation was done to meet the ISO: 3471(2008) E condition. Table- II shows the loads and energy requirement.

Lateral Load $=70000 \times\left(\frac{\mathrm{m}}{20050}\right)^{2.2}$

Vertical Load $=19.61 \mathrm{~m}$

Longitudinal Load $=56000 \mathrm{x}\left(\frac{\mathrm{m}}{20000}\right)^{2.2}$

$\mathrm{U}=\frac{\Delta_{2} F_{2}}{2}+\left(\Delta_{2}-\Delta_{2}\right) \frac{F_{1}+F_{2}}{2}+\cdots+\left(\Delta_{N}-\Delta_{W-2}\right) \frac{F_{W-1}+F_{W}}{2}$

Where,

$\mathrm{F}=$ Force

$\Delta=$ deflection

\section{$\mathrm{U}=$ Energy Absorption}

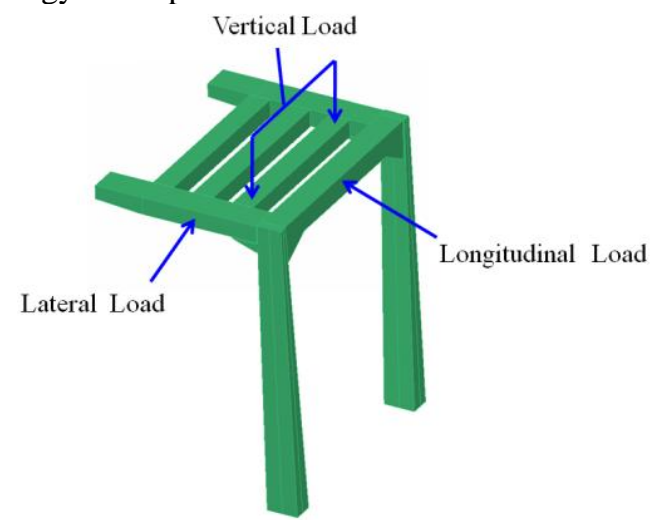

Fig. 6. Depicts the ROPS loads Table- II: Loads on ROPS

\begin{tabular}{|c|c|c|c|}
\hline $\begin{array}{c}\text { Machine } \\
\text { Mass(m) } \\
(\text { Kgs })\end{array}$ & $\begin{array}{c}\text { Lateral load } \\
(\mathrm{N})\end{array}$ & $\begin{array}{c}\text { Lateral load } \\
\text { Energy (J) }\end{array}$ & $\begin{array}{c}\text { Vertical load } \\
(\mathrm{N})\end{array}$ \\
\hline 25750 & 198131 & 48929 & 504958 \\
\hline
\end{tabular}

\section{RESULT AND DISCUSSION}

ROPS Non-linear analysis was conducted as per the ISO: 3471(2008) E [6] standard with all three loads condition. This standard is the basis to determine the appropriate loading, loading points, sequence of loading and allowable displacement and energy absorption requirement of the Rollover protective structure (ROPS). Hence the ROPS was analyzed using Non-Linear explicit finite element software LS-DYNA to determine the non-linear force-displacement characteristic. The results of Von-misses stress and deformation behavior of ROPS were represented in TableIII.

\section{A. Deformation Behavior of ROPS}

Deformation behavior of ROPS is represented below and the criteria considered passing ROPS condition that any of ROPS members should not enter into Deflection limiting volume (DLV). The available safe distance with respect to lateral is $417 \mathrm{~mm}, 415 \mathrm{~mm}$ in vertical and $250 \mathrm{~mm}$ in longitudinal load case as represented in Fig. 2. The maximum deformation results obtained from the FE analysis shown in the Fig. 8 shows lateral deformation of $27 \mathrm{~mm}$, Fig.9 shows maximum vertical deformation of $22 \mathrm{~mm}$, and Fig. 10 shows maximum longitudinal deformation of $87 \mathrm{~mm}$. Deformation value in the entire three load cases are within the limit and safe.

Table- III: Design Characteristics of Two post ROPS

\begin{tabular}{|c|c|c|}
\hline Loads & Deformation, mm & Von-Moises Stress, MPa \\
\hline Lateral & 27.5 & 391 \\
\hline Vertical & 22 & 395 \\
\hline Longitudinal & 87 & 561 \\
\hline
\end{tabular}

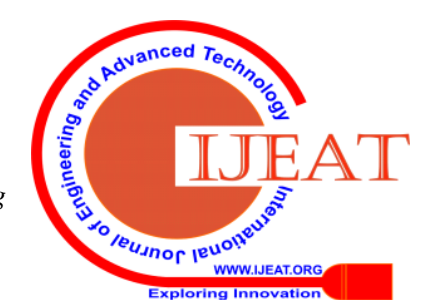




\section{Non-Linear Analysis of a Two Post Roll-Over Protective Structure for Motor Grader}

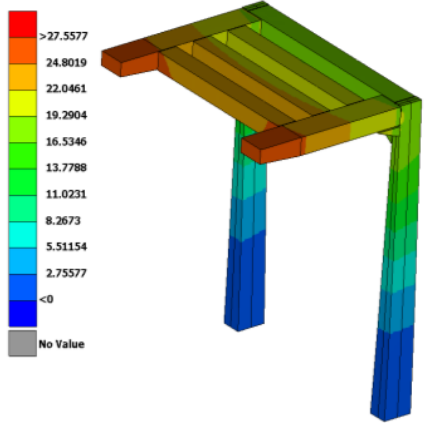

Fig. 7. Deformation at Lateral Load

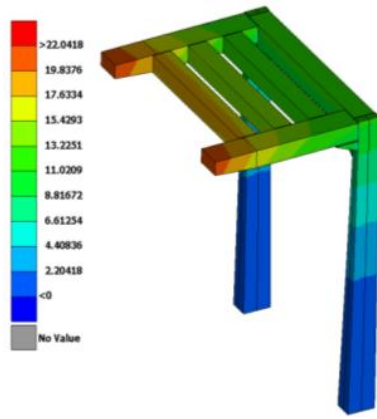

Fig. 8. Deformation at Vertical Load

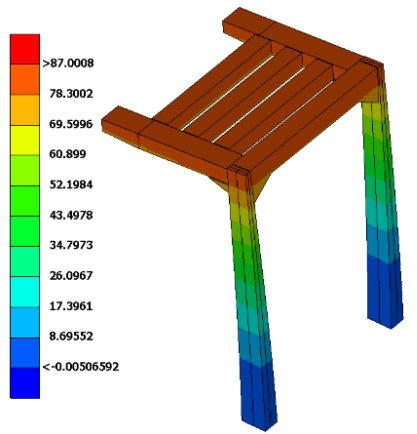

Fig. 9. Deformation at Longitudinal Load

\section{B. Von-Moises Stress of ROPS}

The distribution of Von-Moises stress during application of the peak lateral load is shown in the Fig.11, the result shows that the significant yielding taking place near ROPS column bottom and top portion. Under the vertical load condition, the maximum stress was noticed along the ROPS column and at the corner joints of ROPS column as shown in the Fig.12. the results reveal that the ROPS column with the energy absorber shows less von-misses stress value under the lateral load condition Fig.13 shows Von-Moises stress at Longitudinal Load. Among all the loads, the lateral load dominates the most and causes ROPS column failure. It is evident from the literature study that most of the ROPS failure is due to the vehicle roll at its side during the rollover accident, which is lateral load condition. Therefore, this research on non-linear behavior of the ROPS under the lateral load condition and energy absorption of ROPS was considered to understand the failure behavior. With connection to the energy absorption capacity of ROPS as per ISO: 3471 was calculated based on the Gross Vehicle Weight. In this present study, GVW of motor grader is $25750 \mathrm{~kg}$ approximately. And calculated energy level is $48973 \mathrm{~J}$. The non-linear analysis of ROPS was analyzed through simulation, it is found that energy absorption of $64470.8 \mathrm{~J}$ under the lateral load of $264 \mathrm{kN}$, and the simulation results were shown the Table- IV. From the results, it is concluded that the energy absorption is more than the calculated energy as per ISO: 3471(2008) E standard, hence the designed ROPS with the interweave cross section is safe and meets the standard performance requirement.

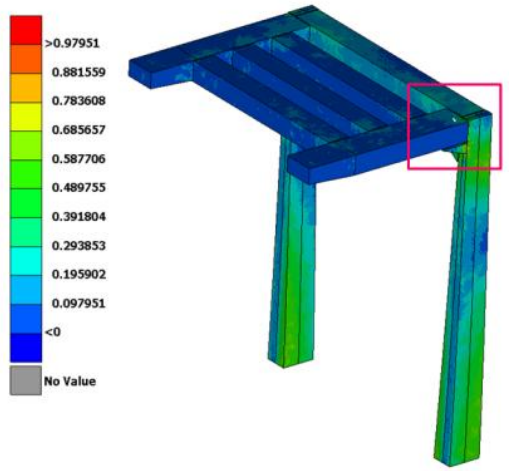

Fig. 10. Von-Moises stress at Lateral Load

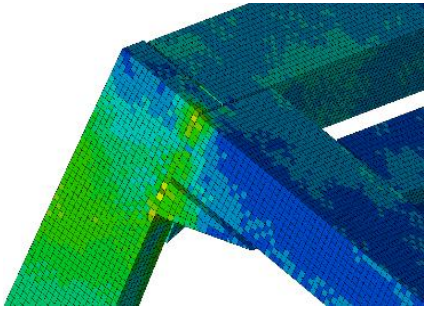

Fig. 11. Von-Mises stress at Lateral Load

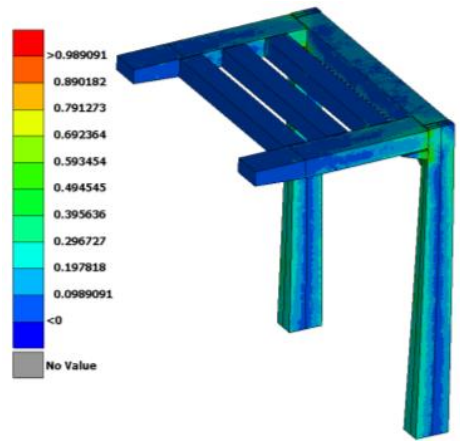

Fig. 12. Von-Moises stress at Vertical Load

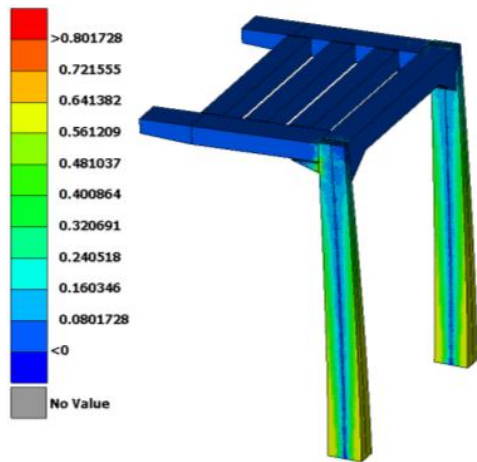

Fig. 13. Von-Moises stress in Longitudinal Load

The deformation behavior of ROPS is directly proportional to the lateral load. Fig.14 shows the lateral load vs. deformation plot obtained from FE analysis. This curve is dependent on several factors including the cross-section stiffness that includes the material and geometric stiffness. Fig. no 15 depicts the curve of internal energy of ROPS verses time.
Published By:

Blue Eyes Intelligence Engineering \& Sciences Publication (c) Copyright: All rights reserved.

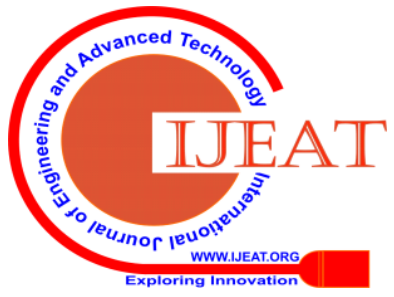


The curve clearly indicates that ROPS structure has capability to absorb the energy during the roll-over condition and the energy absorption capacity remains constant with increase of time.Non-linear explicit analysis is the testing and evaluation of a program by executing data in real-time. The ROPS displacement behavior was studied with respect to the time factor. Fig.16 shows the lateral displacement vs. time plot obtained from FE analysis. The curve shows $27 \mathrm{~mm}$ deformation notice in 120 milliseconds.

Fig.17 and Fig.18 shows the vertical, Longitudinal displacement vs. time plot obtained from FE analysis.

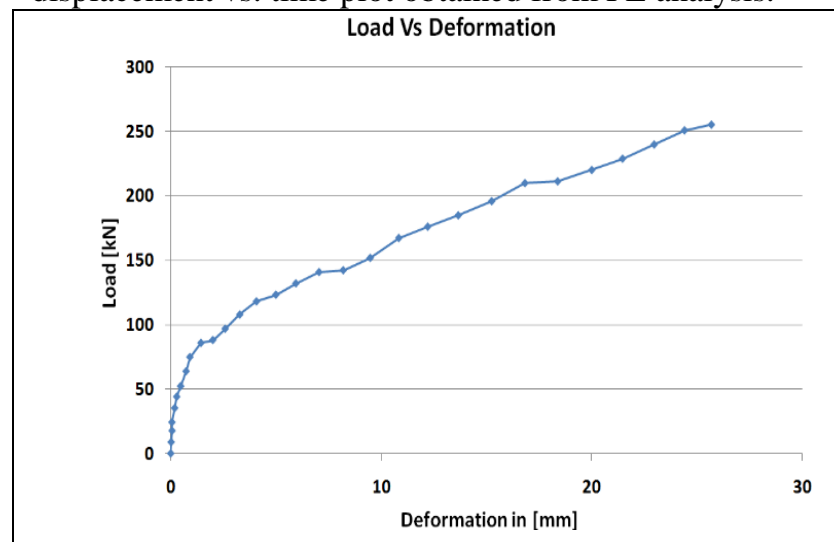

Fig. 14. Lateral Load Vs Lateral Deformation

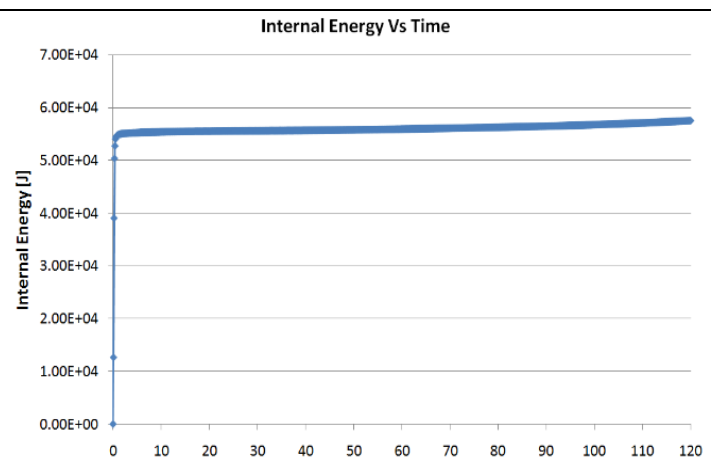

Time[ms]

Fig. 15.Internal Energy Vs Time

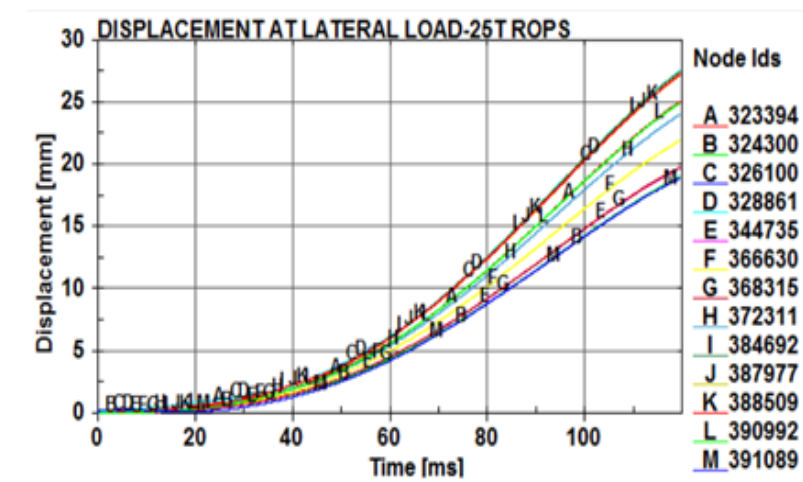

Fig. 16.Displacement Vs Time in Lateral load

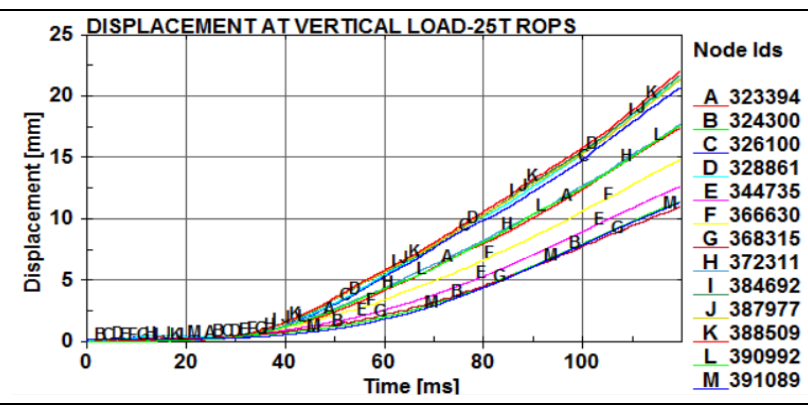

Fig. 17.Displacement Vs Time in Vertical load

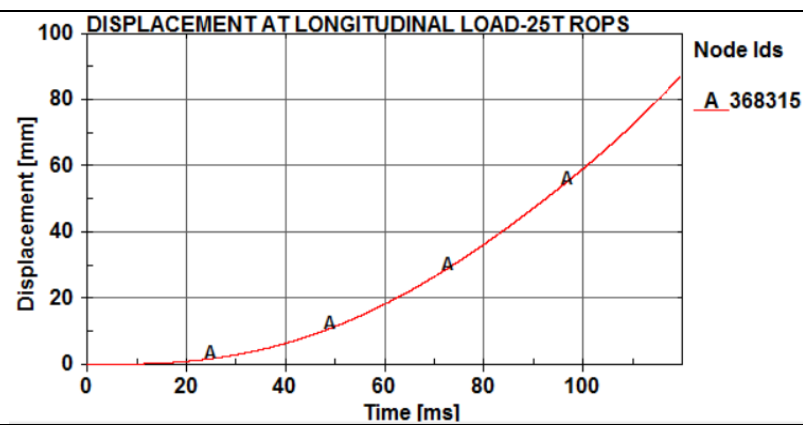

Fig. 18. Displacement Vs Time in Longitudinal load Table- IV: Nonlinear response of two post ROPS for Motor Grader with 25T GVW

\begin{tabular}{|c|c|c|c|}
\hline $\begin{array}{c}\text { Time, } \\
\text { (Milliseconds) }\end{array}$ & $\begin{array}{l}\text { Displacement, } \\
\text { mm }\end{array}$ & Load, KN & Energy, J \\
\hline 0 & 0 & 0 & 0 \\
\hline 4 & 0.0209 & 8.8 & 60342.4 \\
\hline 8 & 0.0628 & 17.6 & 60513 \\
\hline 12 & 0.05838 & 24.2 & 60628.2 \\
\hline 16 & 0.1902 & 35.2 & 60708.8 \\
\hline 20 & 0.2862 & 44 & 60764 \\
\hline 24 & 0.4675 & 52.2 & 60816.9 \\
\hline 28 & 0.7288 & 63.8 & 60854.6 \\
\hline 32 & 0.9078 & 74.8 & 60903.6 \\
\hline 36 & 1.4374 & 85.8 & 60942.5 \\
\hline 40 & 1.9987 & 88 & 60982.5 \\
\hline 44 & 2.5846 & 96.8 & 61022.1 \\
\hline 48 & 3.2798 & 107.8 & 61074.2 \\
\hline 52 & 4.0728 & 118 & 61109.2 \\
\hline 56 & 4.9972 & 123.2 & 61161.7 \\
\hline 60 & 5.9467 & 132 & 61226.9 \\
\hline 64 & 7.0483 & 140.8 & 61313.3 \\
\hline 68 & 8.1967 & 142.2 & 61433.4 \\
\hline 72 & 9.4762 & 151.8 & 61523.2 \\
\hline 76 & 10.838 & 167.2 & 61662.3 \\
\hline 80 & 12.2119 & 176 & 61821.7 \\
\hline 84 & 13.665 & 184.8 & 62012 \\
\hline 88 & 15.2502 & 195.8 & 62218.6 \\
\hline 92 & 16.8299 & 209.8 & 62455.5 \\
\hline 96 & 18.383 & 211.2 & 62717.5 \\
\hline 100 & 20.0039 & 220 & 62989.6 \\
\hline 104 & 21.4693 & 228.8 & 63288.2 \\
\hline 108 & 22.9728 & 239.8 & 63600.1 \\
\hline 112 & 24.414 & 250.8 & 63896.3 \\
\hline 116 & 25.692 & 255.2 & 6419402 \\
\hline 120 & 26.9119 & 264 & 64470.2 \\
\hline
\end{tabular}

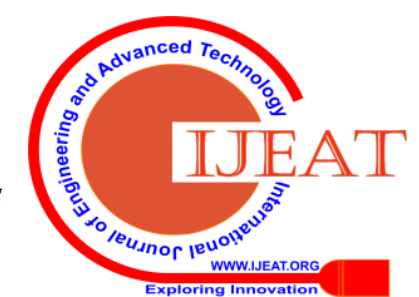




\section{Non-Linear Analysis of a Two Post Roll-Over Protective Structure for Motor Grader}

\section{CONCLUSION}

The following are findings arrived by conducting non-linear behavior of a two - post ROPS of motor grader,

1. Energy absorption capacity of a roll over protective structure (ROPS) was enhanced by introducing a interweave cross section in the each of ROPS column.

2. ROPS column with an interweave cross section which provides better structural rigidity.

3. Lateral, Vertical and Longitudinal deformations are within the safe limit with respect to DLV.

4. The lateral load versus deformation curves shows the energy absorption is more than the calculated energy as per ISO 3471(2008) standard. Hence the designed ROPS with the interweave cross section is safe and meets the standard performance requirement.

\section{REFERENCES}

1. Clark, B.J. and Thambiratnam, David P. and Perera, N.J. 'Analytical and Experimental Investigation of the Behavior of a Rollover Protective Structure' The Structural Engineer. 84(1): pp. 29-34 (2006)

2. Jacek Karlinski, Eugeniusz Rusinski, Tadeusz Smolnicki (2008) 'Protective structures for construction and mining machine operator' Automation in Construction 17 232-24 (2008)

3. Jimmie W. Hinze, Jochen Teizer , (2011) 'Visibility-related fatalities related to construction equipment'Safety Science 49 (2011) 709-718, Elsevier Ltd

4. D. P. Thambiratnam, B. J. Clark, and N. J. Perera, 'Performance of a Rollover Protective Structure for a Bulldozer' Journal of Engineering Mechanics, Vol. 135, January 1, pp.31-40 (2009)

5. A. Mandal, D. Sengupta, 'The analysis of fatal accident in Indian coal mines' Indian statistical institute, 203 BT Road culcutta-700035, AMS classification number, primary 6207, secondary 62P99, 62N05

6. International standard-3471: (2008) E "Earth-moving machinery -Roll-over protective structures - laboratory tests and performance requirements", (2008)

7. International standard-3164 "Earth-moving machinery -Specification for deflection limiting volume.

8. IS: 2062-2011 Hot rolled medium and high tensile structural steel -Specification.

\section{AUTHORS PROFILE}

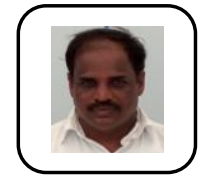

Kumar V, Research Scholar, Department of Mechanical Engineering Sri Jayachamarajendra College of Engineering, Mysore, Karnataka, India, Presented a Research paper in International Conference on Mechanical Design (IC MechD 2019) in SSN College of Engineering, Chennai, India,

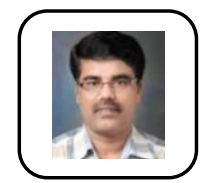

Dr. Mallesh G is Professor in the Department of Mechanical Engineering, Sri Jayachamarajendra College of Engineering, Mysore, Karnataka, India, He graduated from the Mysore University and obtained his Master's Degree and Doctoral Degree from Visvesvaraya Technological University. He works in the area of Mechanical Engineering with particular reference to studies related Asymmetric spur gear design and Analysis, Finite Element Analyses, Fatigue and Fracture Analysis of composite Materials using Micro structured based Finite element analysis.

Radhakrishna K R, Executive Director, Quality BEML Limited, BEML Soudha, SR Nagar, Bengaluru 560027, Karnataka, India. Email: edq@beml.co.in.

Phone: +91 8022963393 